\title{
MOBILIZATION OF NANO ZERO VALENT IRON (n-ZVI) PARTICLES IN SUBSURFACE
}

\author{
Yangdup Lama1, Alok Sinha ${ }^{2}$, Gurdeep Singh ${ }^{3}$ \\ ${ }^{1}$ Research Scholar, ${ }^{2}$ Assistant Professor, ${ }^{3}$ Professor, Department of Environmental Science and Engineering, Indian \\ School of Mines, Dhanbad, aloksinha11@yahoo.com
}

\begin{abstract}
Mobility and stability of nano Zero Valent Iron (n-ZVI), in subsurface, for in-situ remediation of groundwater, has been an issue of concern. This may be enhanced by adding various surfactants to n-ZVI slurry. This study was conducted to determine the effect of surfactants like Poly (Acrylic Acid) (PAA), anionic part of Sapindus mukorossi (reetha) extract and Tween 20, at different volume percentages, on the stability and mobility of $n$-ZVI slurry, through sand and loamy sand column. Results indicate that PAA-modified n-ZVI slurry had maximum mobility and stability through both the soil column followed by reetha-modified and Tween 20 modified $n$ ZVI slurry.
\end{abstract}

Index Terms: Nano Zero Valent Iron (n-ZVI), Ground Water, In-Situ Remediation, Polyelectrolytes, Surfactants. ****

\section{INTRODUCTION}

In the recent years there has been an increasing interest in the in-situ remediation of groundwater contaminated with chlorinated solvents and heavy metals by direct injection of nano zero valent iron (n-ZVI) [1-5]. The in-situ injection technology is more advantageous as compared to the traditional passive processes like "funnel and gate" or the permeable reactive barrier (PRB) processes [6]. They react with contaminants in the source zone and substantially reduce remediation cost and time [6]. n-ZVI have high reactivity with contaminants due to their high surface volume and are relatively resistant to fouling from groundwater contaminants $[7,8]$. However, high reactivity alone is not enough to appoint this promising technology as a good in-situ remediation tool. Simultaneously, n-ZVI needs to be properly dispersed in water for it to migrate through the water-saturated media to the contaminated zone. With relatively high values of ionic strength of groundwater reduction of electrostatic repulsion between particles is favored and colloidal agglomeration of nZVI in water is enhanced [8]. The agglomeration of this n-ZVI is a key technical failure this promising technology faces, due to which the delivery of the n-ZVI to contamination sources in soil and groundwater offers a great challenge [9-10]. It is due to the direct inter particle interactions like van-de-Waals force and magnetic interactions these nano-irons agglomerates which reduce the specific surface area and interfacial free energy, eventually reducing its reactivity [10].

In order to overcome the drawback in the transport property of n-ZVI a common strategy to increase the repulsive electrostatic forces have been studied and implemented. The use of certain polymeric materials to stabilize $n-Z V I$ in water is reported in several studies. The use of a wide variety of polymers including poly acrylic acid (PAA), polyvinyl alcohol-co-vinyl acetate-co-itaconic acid (PV3A), polyaspartate (PAP), Tween 20 and biopolymer such as soy proteins, starch, and carboxymethyl cellulose (CMC) [9-13, 25].have been reported so far. PAA is the first polymer used to stabilize the dispersion of n-ZVI for the field remediation whereas CMC has been recently introduced [14]. By the virtue of the presence of a polar anchoring groups (e.g., $-\mathrm{COOH},-$ $\mathrm{OH},-\mathrm{C} \mathrm{O}$ ) and a stabilizing hydrocarbon chain in the polymers, it can act effectively in stabilizing n-ZVI in water. The anchoring group gets attached onto the surface of $n-Z V I$ and the long hydrocarbon chain can move freely in water to obtain various desired configuration. When these flexible chains overlap the electrostatic and steric repulsion between particles is produced and thus stabilizes the particle under certain conditions [15]. Saponin is one of the most commonly known plant based surfactants. Saponin is largely found in plants like Sapindus mukorossi, soyabean [16], Quillaja bark [17] and Fagonia indica [18].

In this paper, we explore the use of three surfactants namely Polyacrylic Acid (PAA), Tween 20 and anionic extract of Reetha (Sapindus mukorossi) in order to improve the motility of nano iron slurry in porous media as compared to n-ZVI without surfactants along with the stability of prepared nano iron slurries.

\section{MATERIALS AND METHODS}

\subsection{Materials}

All chemicals used in this work are AR grade unless otherwise specified. Except for anionic extract of reetha, the other two 
surfactants are commercial products. Polyacrylic acid (PAA) was procured from Otto Chemika; Tween 20 (Polyoxyethylene sorbitan monolaurete) was obtained from Sigma Life Science. The chemicals for the preparation of nanoiron particles were FeSO4.7H2O from Loba Chem and $\mathrm{NaBH} 4$ from Loba Chem. The Cation exchange resin used for preparation of anionic reetha extract was DOWEX 50 X8(Na) obtained from Loba Chem.Sand and loamy soil were obtained form the local areas of Dhanbad. They were sieved through $2 \mathrm{~mm}$ sieve, washed with distilled water and heated in the oven before use.

\subsection{Iron Based Nanoparticles}

Synthesis of nanoscale zerovalent iron particles was achieved by adding $0.04 \mathrm{~mol} / \mathrm{L} \mathrm{FeSO}_{4} \cdot 7 \mathrm{H}_{2} \mathrm{O}$ aqueous solution drop wise to a three-necked flask containing $0.08 \mathrm{~mol} / \mathrm{L} \mathrm{NaBH}_{4}$ aqueous solution at ambient temperature [19]. The process was performed in Ar atmosphere. Ferric iron was reduced by borohydrate according to the following reaction [20]:

$\mathrm{Fe}\left(\mathrm{H}_{2} \mathrm{O}\right)_{6}^{2+}+2 \mathrm{BH}_{4}^{-} \rightarrow \mathrm{Fe}^{0} \downarrow+2 \mathrm{~B}(\mathrm{OH})_{3}+7 \mathrm{H}_{2} \uparrow$

Synthesized iron particles were deposited for $4 \mathrm{~h}$ in $\mathrm{Ar}$ atmosphere, and washed with ethanol. Then they were washed with deionized water after deposition for $3 \mathrm{~h}$. After the preparation of nanoiron particles, the desired amount of the selected surfactant were added to the nano iron suspension and mixed vigorously.

Table 1: Recipes for different nanoiron slurry

\begin{tabular}{|l|l|l|}
\hline $\begin{array}{l}\text { Test } \\
\text { No. }\end{array}$ & Type of Surfactant & $\begin{array}{l}\text { Amount of } \\
\text { surfactant } \\
\text { added (vol \%) }\end{array}$ \\
\hline 1 & PAA & 1 \\
\hline 2 & PAA & 2 \\
\hline 3 & PAA & 3 \\
\hline 4 & PAA & 5 \\
\hline 5 & Reetha Extract & 1 \\
\hline 6 & Reetha Extract & 2 \\
\hline 7 & Reetha Extract & 3 \\
\hline 8 & Reetha Extract & 5 \\
\hline 9 & Tween 20 & 1 \\
\hline 10 & Tween 20 & 2 \\
\hline 11 & Tween 20 & 3 \\
\hline 12 & Tween 20 & 5 \\
\hline
\end{tabular}

\subsection{Preparation of Anionic Extract of Reetha}

The Reetha (Sapindus trifoliata) seeds were soaked in distilled water $(0.5 \mathrm{~kg}$ Reetha seeds $/ \mathrm{L})$ for two days and mashed. The extract was filtered first through a cotton cloth followed by a combination of glass-fiber prefilter and a $0.45 \mathrm{~mm}$ Millipore GF-C filter. Through cation-exchange column containing DOWEX 50 X8 $(\mathrm{Na})$ resin $50 \mathrm{~mL}$ of the bulk Reetha extract was passed. The cation exchange columns were eluted using $50 \mathrm{~mL}$ of Milli-Q water each, to obtain the cationic fractions of the Reetha extract [21].

\subsection{Stability of Nanoiron Slurries}

The stability of various nanoiron slurries was visually evaluated by gravitational sedimentation of nanoiron within. $100 \mathrm{ml}$ of well mixed slurry was poured into a $100 \mathrm{ml}$ of glass measuring cylinder and observations were made after every hour. A control test of nanoiron slurry with no surfactant was also carried out. Test were carried out in batches of four with different concentrations of surfactants $(1 \%, 2 \%, 3 \%$ and $5 \%)$ (Table1).

\subsection{Column Experiments}

Glass burette columns were used to compare the transport behaviour of different nanoiron slurries. The experimental set up was similar to that of Schrick et al. [11] where the column ends were packed with glass wool plugs to prevent the drainage of both soil and iron particles. Columns were filled with sandy loam soil up to the height of $15 \mathrm{~cm}$ before the addition of nanoiron slurries. The experiments were carried out in a batch of four for all the different concentrations of surfactants and a control which comprised of only nanoiron particles. After the tests were done for sandy loam, test with sand were carried with similar experimental setup and conditions.

In the column studies, the stock solution of suspended iron nano particles $(3 \mathrm{mg} / \mathrm{mL})$ were introduced to the top of the column continuously and an eluent was collected in $2 \mathrm{ml}$ fraction. For the analysis of this eluent $3 \mathrm{~mL}$ of aqueous orthophenanthroline (Aldrich, 3mg/mL) solution was added. Complex formed was measured at $508 \mathrm{~nm}$ [22]. If PAA used as surfactant the analysis is carried out as follows: $2.0 \mathrm{ml}$ of ortho-phenanthroline $(3 \mathrm{mg} / \mathrm{mL})$ aqueous solution and $1 \mathrm{~mL}$ of $6 \mathrm{M} \mathrm{HCl}$ are mixed to each aliquot and the mixture is centrifuge at $14000 \mathrm{rpm}$ for 30 minutes. The amount of iron in the supernatant is determined by absorbance at $508 \mathrm{~nm}$.

\section{RESULTS AND DISCUSSIONS}

\subsection{Stability of Nanoiron Slurries}

The settling behaviour of various nano iron slurries prepared by adding different surfactants were observed for a period of 6 hours where observations were made after every hour. A distinctive result was observed after four hours which can be seen in the figure 1 . For the nanoiron slurry without any surfactant almost all the nano iron particles settled down accompanied by the formation of thin lumpy layer at the top of 
the column. For the nanoiron slurry with Tween 20, no appreciable stability was observed. The anionic extract of reetha showed a slight improvement in stability but a yellowish colour layer was formed on top of the column which is due to oxidation of the nanoiron. A satisfactory result was observed with PAA where the n-ZVI was still found in a dispersed state with no sign of oxidation. This observation is in good agreement with report of other researches [11, 23-24] where it was reported that PAA is a good agent for enhancing the motility of $n-Z V I$. The effective use of other anionic surfactants like PV3A and sodiumdoceyl benzensulfonate has also been reported $[13,26]$. Bearing in mind the highest level of stability offered by PAA the column studies were carried on.

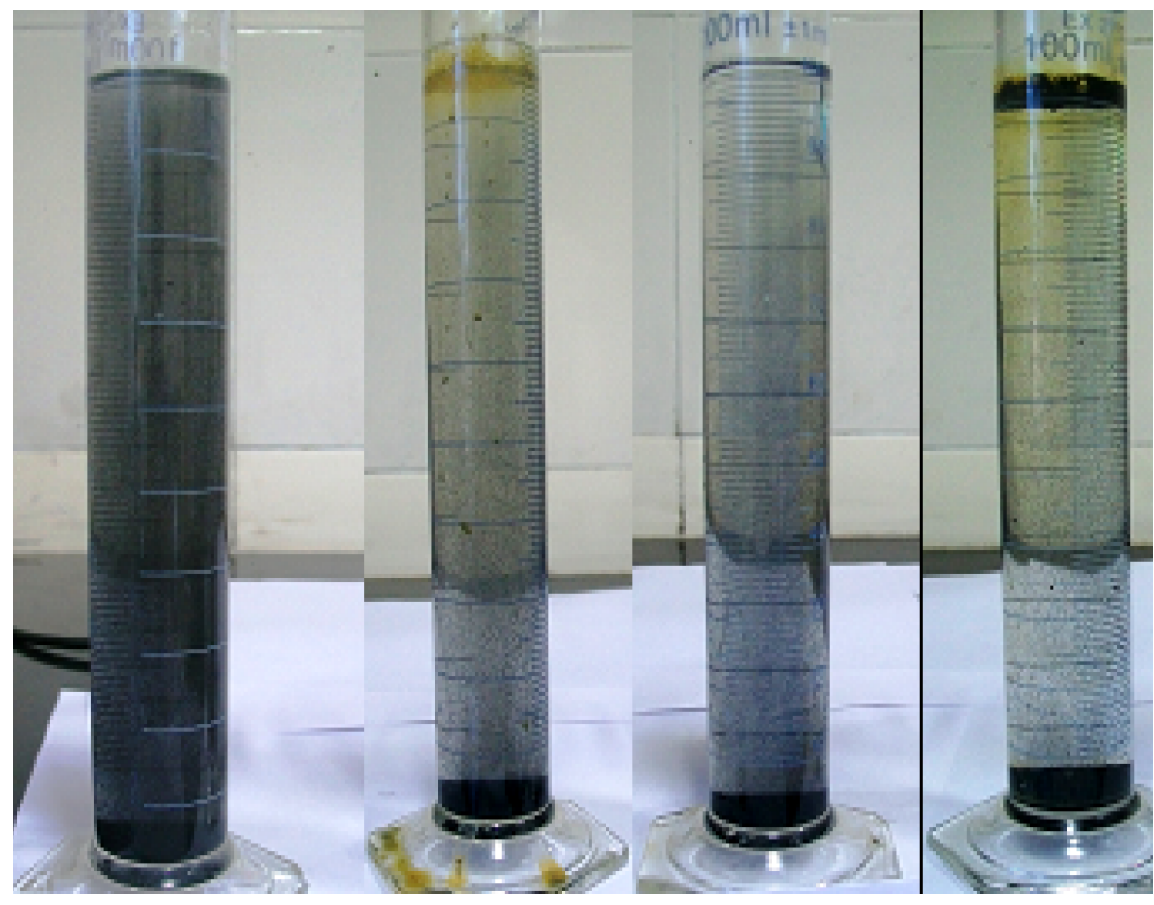

Surfactant: PAA (2\%) Reetha Extract (2\%) Tween $20(2 \%) \quad$ No surfactant

Figure 1: Effect of surfactants on the dispersion of n-ZVI after settling for 4 hours.

\subsection{Column Studies}

The column studies are carried out to measure the effects of surfactants on the overall particle transport. For n-ZVI, with no surfactant, only aqueous solution passed through the sandy loam and sand column, with the aggregated mass of nanoiron retained on the top of the column. The immobility of these nanoiron particles was mainly due to the instant agglomeration of the nanoparticles in absence of surfactants. As for n-ZVI with PAA (2\%), it was observed the nanoiron particles easily passed through the sand as well and sandy loam column, with the sandy loam column offering more resistance than sand. Figure 2 and 3 gives the effect of the three surfactants PAA, reetha extract and Tween 20 on the flow of $n-Z V I$ through both the columns as per the concentration of $n-Z V I$ eluted from the column in constant volume. The efficiency of the surfactants followed the trend: PAA, anionic extract of reetha and Tween 40. Similar kind of trend was also observed in Schrick et al., 2004 where only $40 \%$ of Fe/PAA injected were retained in the soil columns. The flow rate of the slurries were also recorded with the Fe/PAA showing the highest flow rate of $7.5 \mathrm{ml} / \mathrm{min}$ through the sand column as compared to 6.0 $\mathrm{ml} / \mathrm{min}$ through the sandy loam column. Similarly, the Reetha extract and Tween 20 modified n-ZVI observed the flow rate of $3.5 \mathrm{ml} / \mathrm{min}$ and $2.3 \mathrm{ml} / \mathrm{min}$ through the sand column, respectively and $2.0 \mathrm{ml} / \mathrm{min}$ and $1.5 \mathrm{ml} / \mathrm{min}$ through the sandy loam column, respectively. The sand column observed a flow rate of $\mathrm{Fe} / \mathrm{PAA}>10 \mathrm{ml} / \mathrm{min}$ and $1-5 \mathrm{~mL} / \mathrm{min}$ in sandy loam column. Both the flow rate and the concentration of eluted nanoiron are observed to be high in case of sand column as compared to sandy loam column. The main reason being that the sandy loam has $15-20 \%$ silt, due to which, the particles impede the flow of n-ZVI slurry through the column [11]. Previous works by researchers have confirmed that PAA binding to $n-Z V I$ creating highly negative surfaces effectively reduces the filtration removal by aquifer materials [11, 23-24]. Based upon this work, the results confirmed that the transport 
efficiency of n-ZVI in porous media can be enhanced by the increase of the PAA dosage.

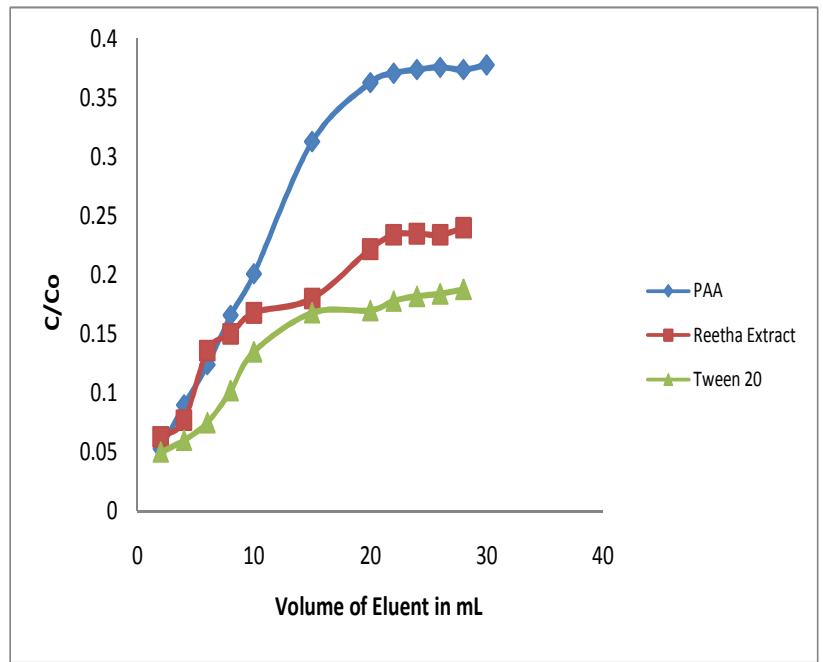

Figure 2: Effect of surfactant on the n-ZVI concentration eluted from soil column.

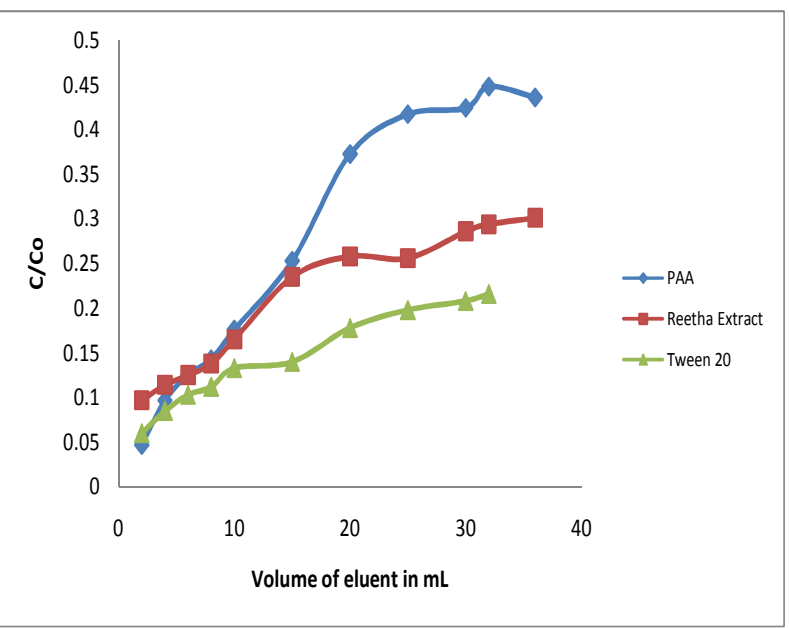

Figure 3: Effect of surfactant on the n-ZVI concentration eluted from sand column.

\section{CONCLUSIONS}

The establishment of the stability of n-ZVI slurry to enhance its motility through soil is very important for in-situ remediation of groundwater. The addition of PAA would greatly enhance the stability of nano iron slurry followed by reetha extract and Tween 20. The transport behaviour of $n-$ ZVI is very different in different soil depending largely on their texture ad characteristics. In the real groundwater and soil condition the interception of n-ZVI is equally important for remediation purpose. Hence to minimise this interception of n-ZVI slurries due to various soil particles by the use of surfactants can show positive results in enhancing the motility of n-ZVI slurry.

\section{ACKNOWLEDGEMENTS}

The author heartily acknowledge ISM authorities for providing all necessary assistance, under the research project FRS (1)/2009-2010/1/ESE, for completion of this research work.

\section{REFERENCES}

[1]. Gillham, R.W. and Burris, D.R. (1992) Recent developments in permeable in situ treatment walls for remediation of contaminated groundwater: Proceedings, Subsurface Restoration Conference, June 21-24, 1992, Dallas, Tex.

[2]. Scherer, M. M., Richter, S., Valentine, R. L., and Alvarez, P. J. J. (2000) Chemistry and microbiology of permeable reactive barriers for in situ groundwater clean up. Crit. Rev. Environ. Sci. Technol. 30, 363411.

[3]. Tratnyek, P. G., Scherer, M. M., Johnson, T. J., and Matheson, L. J. (2003) Permeable reactive barriers of iron and other zero-valent metals. In Chemical Degradation Methods for Wastes and Pollutants: Environmental and Industrial Applications; Tarr, M. A., Ed.; Marcel Dekker: New York, pp 371-421.

[4]. Day, S. R., O’Hannesin, S. F., and Marsden, L. (1999) Geotechnical techniques for the construction of reactive barriers. J. Hazard. Mater. 67, 285-297.

[5]. Zhang, W.X. (2003) Nanoscale iron particles for environmental remediation. J. Nanopart. Res. 5, 323332.

[6]. Cheng, R., Wang, J. L., Zhang, W. X. (2006) The research progress on degradation of halogenated organic compounds by nano iron. Progress in Chem, 18, 93-99.

[7]. Cantrell, K. J. and Kaplan, D. I. (1997) Zero-valent iron colloid emplacement in sand columns. J. Environ. Eng. 123, 499-505.

[8]. Saleh, N., Phenrat, T., Sirk, K., Dufour, B., Ok, J., Sarbu, T., Matyjaszewski, K., Tilton, R. D., and Lowry, G. V. (2005) Adsorbed triblock copolymers deliver reactive iron nanoparticles to the oil/water interface. Nano Lett. 5, 2489-2494.

[9]. Tiraferri, A., Chen, K. L., Sethi, R., and Elimelech, M. (2008) Reduced aggregation and sedimentation of zerovalent iron nanoparticles in the presence of guar gum. J. Colloid Interface Sci. 324, 71-79.

[10]. Kim, H.J., Phenrat, T., Tilton, R.D., and Lowry, G.V. (2009) $\mathrm{Fe} 0$ nanoparticles remain mobile in porous media after aging due to slow desorption of polymeric surface modifiers, Environ. Sci. Technol. 43, 38243830 . 
[11]. Schrick. B.,. Hydutsky, B.W., Blough, J.L., and Mallouk, T.E. (2004) Delivery vehicles for zerovalent metal nanoparticles in soil and groundwater, Chem. Mater. 16, 2187-2193.

[12]. He, F. and Zhao, D.Y. (2005) Preparation and characterization of a new class of starchstabilized bimetallic nanoparticles for degradation of chlorinated hydrocarbons in water, Environ. Sci. Technol. 39, 3314-3320

[13]. Saleh, N., Sirk, K., Liu, Y., Phenrat, T., Dufour, B., Matyjaszewski, K., Tilton, R.D. and Lowry, G.V. (2007) Surface modifications enhance nanoiron transport and NAPL targeting in saturated porous media, Environ. Eng. Sci. 24, 45-57.

[14]. He, F., Zhao, D., and Paul, C. (2010) Field assessment of carboxymethyl cellulose stabilized iron nanoparticles for in situ destruction of chlorinated solvents in source zones, Water Res. 44, 2360-2370.

[15]. Everett, D.H. (1989) Basic Principles of Colloid Science, Royal Society of Chemistry, London.

[16]. Berhow, M.A., Wagner, E.D., Vaughn, S.F. and Plewa, M.J. (2000) Characterization and antimutagenic activity of soybean saponins. Mut. Res. 448(1), 11-22.

[17]. Mitra, S. and Dungun, S. (1997) Micellar properties of Quillaja saponin. Effects of temperature, salt and $\mathrm{pH}$ solution properties. J. Agric. Food Chem. 45(5), 15871595.

[18]. Shaker, K.H., Bernhardt, M., Elgamal, M.H.A. and Seifert, K. (1999) Triterpenoid saponins from Fagonia indica. Phytochem. 51(8), 1049-1053.

[19]. Cheng, R., Wang, J.L., and Zhang, W.X. (2007) Reductive Dechlorination of p-Chlorophenol by Nanoscale Iron. Biomed and Envn Sc. 20, 410-413.

[20]. Glavee, G. N., Klabunde, K. J., Sorensen, C. M., Hadjipanayis, G.C. (1995) Chemistry of Borohydride Reduction of Iron (II) and Iron (III) Ions in Aqueous and Nonaqueous Media. Formation of Nanoscale Fe, $\mathrm{FeB}$, and FeB Powders. Inorg Chem 34, 28-35.

[21]. Tiwari, M.K., Guha, S., Harendranath, C.S., and Tripathi, S. (2005) Enhanced granulation by natural ionic polymer additives in UASB reactor treating lowstrength wastewater. Water Research 39, 3801-3810.

[22]. Skoog, D. A. and West, D. M. (1986) Analytical Chemistry, 4th ed.; Saunders College Publishing: Philadelphia, PA, 612-613.

[23]. Yang, G.C.C., Tu, H.C., and Hung, C.H. (2007) Stability of Nanoiron slurrie and their transport in subsurface environment. Separation and Purification technology 58,166-172.

[24]. Jiemvarangku, P., Zhang, W. and Lien, H.L. (2011) Enhanced transport of polyelectrolyte stabilized nanoscale zero-valent iron (n-ZVI) in porous media. Chemical Engineering Journal 170, 482-491.

[25]. Phenrat, T., Saleh, N., Sirk, K., Kim, H., Tilton, R.D., and Lowry, G.V. (2008) Stabilization of aqueous nanoscale zerovalent iron dispersions by anionic polyelectrolytes: adsorbed anionic polyelectrolyte layer properties and their effect on aggregation and sedimentation, J. Nanopart. Res. 10, 795-814.

[26]. Sun, Y.P., Li, X., Cao, J., Zhang, W., and Wang, H.P. (2006) Characterization of zero-valent iron nanoparticles, Adv. Coll. Interf. Sci. 120, 47-56. 